\title{
Residential treatment for homeless female veterans with psychiatric and substance use disorders: Effect on 1-year clinical outcomes
}

\author{
Ilan Harpaz-Rotem, PhD; ${ }^{1-2 *}$ Robert A. Rosenheck, MD; ${ }^{2-3}$ Rani Desai, PhD, MPH ${ }^{2,4}$ \\ ${ }^{1}$ Clinical Neurosciences Division, National Center for Posttraumatic Stress Disorder, Department of Veterans Affairs \\ (VA) Connecticut Healthcare System, West Haven, CT; ${ }^{2}$ Department of Psychiatry, Yale University School of Medicine, \\ New Haven, CT; ${ }^{3}$ New England Mental Illness Research, Education, and Clinical Center, VA Connecticut Healthcare \\ System, West Haven, CT; ${ }^{4}$ Northeast Program Evaluation Center, VA Connecticut Healthcare System, West Haven, CT
}

\begin{abstract}
Limited evidence shows that time-limited residential treatment (RT) is beneficial for homeless people with serious mental illness. The Department of Veterans Affairs has established 11 specialty programs for homeless female veterans. We present data comparing 1-year clinical outcomes in a group of veterans who did and did not receive at least 30 days of RT. Clients of the Homeless Women Veterans Programs were invited to participate in a follow-up study. They were interviewed every 3 months for 1 year. Those who received at least 30 days of RT in the 3 months after program entry (RT group) were compared with other program participants (no or $<30$ days RT [NRT] group) on measures of community functioning, psychiatric symptoms, and drug and alcohol use during the follow-up. The RT group had better outcomes on employment, social support, housing status, and psychiatric symptoms. They also had significantly increased use of drugs and alcohol compared with the NRT group. Data suggest that RT may have a beneficial effect on mental health outcomes in homeless women. This study, in conjunction with others, suggests that provision of stable housing may be an important element of recovery for homeless women with psychiatric problems, excluding substance use.
\end{abstract}

Key words: alcohol, drug, female, homeless, mental health, psychiatric symptoms, PTSD, rehabilitation, residential treatment, veterans.

\section{INTRODUCTION}

It is estimated that in the United States approximately 30 percent of homeless men and 4 percent of homeless women are veterans [1-3]. Epidemiologic studies have indicated that veterans are modestly overrepresented in the homeless population, with large age variation in the risk of homelessness [1,4]. In addition, like other homeless people, homeless veterans are at high risk for serious mental illness, trauma, and substance abuse and dependence [5]. While the number of homeless female veterans is uncertain, epidemiologic research suggests that female veterans are at three to four times increased risk for homelessness compared with their civilian counterparts [2].

Abbreviations: ASI $=$ Addiction Severity Index, HCHV = Health Care for Homeless Veterans, HWVP $=$ Homeless Women Veterans Program, NRT $=$ no (or $<30$ days) residential treatment, PCL $=$ PTSD Symptom Checklist, PTSD $=$ posttraumatic stress disorder, RT = residential treatment, SCL = Symptom Checklist-30, SF-12 = 12-Item Short Form Health Survey, SS = Seeking Safety, VA = Department of Veterans Affairs, VAMC $=$ VA medical center.

* Address all correspondence to Ilan Harpaz-Rotem, PhD; Yale University-Psychiatry, 300 George St, Suite 901, 116B, New Haven, CT 06511; 203-937-4760; fax: 203-785-7357.

Email: ilan.harpaz-rotem@yale.edu

DOI:10.1682/JRRD.2010.10.0195 
Over the past 20 years, the Department of Veterans Affairs (VA) has made the issue of serving homeless veterans a high priority. In 1987, the Health Care for Homeless Veterans (HCHV) program was established and provided a core set of services designed to identify homeless veterans in the community; link them with case management services; and streamline access to VA mental health, substance abuse, physical health, and both VA and community residential treatment (RT) services [6].

Modest, and primarily nonexperimental, evidence shows that RT can reduce both psychiatric symptoms and drug and alcohol abuse as well as increase community functioning after discharge, although studies and samples can be difficult to compare because of wide variation in the types of services provided across treatment programs. Randomized studies have indicated significant improvement in psychiatric symptoms and, inconsistently, in substance abuse outcomes for residential substance abuse treatment programs [7-9]. Residential programs focused on psychiatric treatment are sometimes utilized as an alternative to, or step-down from, psychiatric inpatient care [10]. Randomized studies comparing RT with hospitalization generally show no significant group differences in outcomes [11-12]. However, clients have expressed greater satisfaction with community placement, and RT clients have lower healthcare costs [12-13].

Of all veterans receiving services from the VA's HCHV program, about half receive community-based contract RT [14]. In these programs, 4 percent of clients are women, a proportion only slightly lower than the proportion of women in most VA patient populations (5\%) [14]. Thus, little evidence shows that female veterans face gender-specific barriers in obtaining RT through the VA, though wide variation exists across the country in the availability of such services.

An important hypothesis suggests that "to provide the best care to women veterans, it may be important to address their unique health, mental health, and psychosocial needs through specialized programs" [15]. To this end, 11 VA medical centers (VAMCs) were funded to establish a specialized Homeless Women Veterans Program (HWVP). Funds were used to hire staff that would provide outreach, intake, and case management services to women in the program and provide entry into time-limited community-based RT services. This study presents observational data comparing 1-year clinical outcomes among women who received RT services and those who did not.

\section{METHODS}

\section{Sample}

Subjects were recruited between January 2000 and December 2005 from the 11 VAMCs that implemented the specialized HWVPs. "Veterans were eligible for the study if their case manager determined that they were literally homeless, were at high risk of becoming homeless, had not received VA health services for more than 6 weeks at the time of program entry, had psychiatric and/or addiction problems, were cognitively able to complete the assessment interviews, were medically and psychiatrically stable, were interested in participating in available mental health services, and were willing to be interviewed quarterly during a 1-year follow-up period" [15]. Dr. Desai, the study coordinator, reviewed questions about eligibility to ensure consistency in eligibility decisions because structured instruments were not used to determine study eligibility.

Each participant gave written informed consent to participate in the study, and 451 veterans were enrolled in the study. Veterans were only included in analyses if they had completed at least one follow-up interview.

\section{Measures}

The primary independent variable of interest was receipt of RT services for at least 30 days. Those who received $<30$ days of treatment were included in the comparison group. Each program had differing funding for RT services, and the individual programs varied in the array of clinical and rehabilitation services available. Through ongoing monitoring of the contract programs, standardized discharge summaries were completed that documented the date of admission, length of stay, and reasons for the veteran leaving RT. RT is defined as a VA or non-VA contract program that houses clients in a central location and provides clinical and social services to the clients while they are resident. Services are provided by at least some professional staff, though peer counselors can be offered as well, and all veterans are eligible for VA outpatient services. A woman was considered to have received $\mathrm{RT}$ if she had a minimum of 30 days residence in such a program. Women who received either no or $<30$ days of RT were included in the no RT (NRT) comparison group.

Self-report interview data comprised the majority of other study variables. Client characteristics included sociodemographics, employment status, use of public 
support programs such as Medicaid and local government welfare, use of services in non-VA settings in the 3 months prior to program entry, and military history.

"Health status was measured with a variety of standardized self-report measures including the Psychiatric, Alcohol, and Drug composite scales from the Addiction Severity Index (ASI) [16]; the Symptom Checklist-30 (SCL) [17]; a measure of self-esteem; and the 12-Item Short Form Health Survey (SF-12) measures for physical and mental functioning [18]. Extensive trauma histories were obtained on lifetime and recent traumas experienced by each client, and the Posttraumatic Stress Disorder (PTSD) Symptom Checklist (PCL) was used to assess PTSD symptoms [19].

"Housing status at study entry was measured by questions concerning how many days in the previous 90 the veteran had slept in each of 12 types of places. Responses were collapsed into three categories, reflecting the number of days the veteran was homeless, living in an institution (e.g., halfway house, jail, or inpatient unit), or housed (either individually or with others).

"Participants were also asked how many people they felt close to in each of nine relationship categories. A continuous social support variable was computed indicating the total number of persons to whom the client felt close" [15].

\section{Data Analyses}

First, we compared those who did and did not receive RT on baseline characteristics using chi-square and independent samples $t$-tests. "Factors that were significantly different between the groups were then included in multivariable models to adjust for potential confounding. Mixed models for longitudinal data were used to compare outcomes over 1 year, controlling for baseline differences, baseline levels of the outcome of interest, and dropout from the study. Each model included terms representing time, participation in RT for at least 30 days, and the interaction of time and RT group. Time was treated as a categorical variable. Adjustment for characteristics of patients lost to follow-up was made with an interaction between time and the baseline value of the outcome of interest [20]. The analyses were conducted using the MIXED procedure in SAS statistical software" (SAS Institute, Inc; Cary, North Carolina) [15].

\section{RESULTS}

\section{Baseline Characteristics}

At baseline, RT clients had significantly lower total monthly income (Table 1). RT clients were significantly less likely to have minor children, more likely to be black, and less likely to be of "other" race/ethnicity than NRT clients. No baseline differences were noted for days of homelessness, military rank or type of discharge, VA disability ratings, education, days worked in the past 30 , age, or number of months spent homeless in their lifetime.

On clinical measures, RT clients had significantly higher scores on the SF-12 Mental subscale (representing better mental functioning: $p=0.001$ ) and higher ASI Alcohol $(p=0.001)$ and Drug scores $(p=0.001)$ (representing more severe substance abuse problems) (Table 2). However, they did not differ significantly on PTSD symptoms, SF-12 Physical scores, social support, or total number of traumatic events.

In addition to these variables, some clients in the HWVP during the last 2 years of the study were offered a clinical intervention called Seeking Safety (SS). SS is a cognitive-behavioral intervention for substance abuse and trauma. Because it has been found to be modestly associated with clinical outcomes in this sample [15], receipt of this treatment was included as a covariate in multivariable models.

Race/ethnicity, having minor children, monthly income at baseline, self-esteem scores, SF-12 Mental scores, ASI scores, and SS receipt were thus entered into all multivariable longitudinal mixed models of the effects of RT along with baseline measures of the outcome.

\section{Follow-Up Rates}

Table 3 presents the follow-up rates for this evaluation. There were 217 women placed into RT and 234 women who were not in RT during the follow-up. Because funds were not available for additional research personnel, clinicians were tasked with attempting to follow clients both during treatment and after they had dropped out of the HWVP. The difficulty of this challenge is reflected in the modest follow-up rates. The advantage of mixed models, however, is that even clients who dropped out of the study were able to contribute data to the data analysis.

\section{Outcomes}

Table 4 presents the results of multivariate models of outcomes over time, including the significance of the 
JRRD, Volume 48, Number 8, 2011

Table 1.

Sociodemographic characteristics of women with or without residential treatment (RT). Data presented as frequency, $n$ (\%), or mean \pm standard deviation.

\begin{tabular}{|c|c|c|c|c|}
\hline Characteristic & No RT & RT & $\chi^{2}$ or $t$-Value & $p$-Value \\
\hline \multicolumn{5}{|l|}{ Race/Ethnicity } \\
\hline White, Non-Hispanic & 86 (36.9) & 72 (33.2) & 0.69 & 0.41 \\
\hline Black, Non-Hispanic & $106(45.5)$ & 127 (58.5) & 7.64 & 0.006 \\
\hline Hispanic & $21(9.0)$ & $10(4.6)$ & 3.40 & 0.07 \\
\hline Other & $20(8.6)$ & $8(3.7)$ & 4.62 & 0.02 \\
\hline Literally Homeless & $52(22.4)$ & 35 (16.1) & 2.83 & 0.09 \\
\hline Employed Part-Time & $68(29.3)$ & $53(24.4)$ & 1.36 & 0.24 \\
\hline Unemployed & $82(35.3)$ & $83(38.2)$ & 0.41 & 0.52 \\
\hline Have Minor Children ${ }^{*}$ & $86(60.6)$ & $56(39.4)$ & 6.42 & 0.01 \\
\hline \multicolumn{5}{|l|}{ Military Rank } \\
\hline Enlisted & 228 (98.3) & $211(97.7)$ & - & - \\
\hline Dishonorable & $0(0.0)$ & $0(0.0)$ & - & - \\
\hline Other & $28(12.0)$ & $26(12.0)$ & 0.00 & $>0.99$ \\
\hline Age (yr) & $43.5 \pm 8.9$ & $43.9 \pm 6.7$ & 0.59 & 0.56 \\
\hline \multicolumn{5}{|l|}{ Service-Connected Disability (\%) ${ }^{\dagger}$} \\
\hline Physical & $8.2 \pm 17.3$ & $6.3 \pm 16.1$ & 1.03 & 0.30 \\
\hline Psychiatric & $8.9 \pm 23.8$ & $6.1 \pm 20.3$ & 1.13 & 0.27 \\
\hline Education (yr) & $13.5 \pm 1.6$ & $13.5 \pm 1.6$ & 0.10 & 0.92 \\
\hline Lifetime Time Homeless (mo) & $28.0 \pm 44.0$ & $26.0 \pm 31.7$ & 0.53 & 0.59 \\
\hline Days Worked, Past Month & $3.9 \pm 7.5$ & $3.7 \pm 7.9$ & 0.21 & 0.84 \\
\hline Total Income, Past Month (\$) & $666.1 \pm 737.3$ & $510.0 \pm 822.2$ & 2.12 & 0.04 \\
\hline
\end{tabular}

main effects for treatment group and time as well as the significance of the interaction between time and treatment group. For models in which a significant main effect of treatment group was noted, post hoc comparisons were made across groups at each time point. In every case, a significant effect of time was found such that for every outcome observed, significant improvement over time was noted, regardless of RT group.

The RT group had significantly more days worked on average $(p=0.02)$, specifically at 6 months $(p=0.004)$ and 9 months $(p=0.03)$. They also had significantly fewer days homeless over time, particularly at months $3(p<0.001)$ and $6(p=0.004)$, though we should note that nights during RT were not considered to be spent homeless. The RT group had significantly higher social support on average $(p<0.001)$ and at every time point after baseline.
Both groups had significantly decreasing SCL scores over time. The RT group had significantly lower scores on average $(p<0.001)$ and at all time points after baseline. The RT group also had significantly lower PTSD scores on average ( $p=0.001)$, specifically at 3 months $(p=0.01), 6$ months $(p=0.004)$, and 12 months $(p=$ 0.03). However, the overall interaction between RT and time was nonsignificant $(p=0.09)$.

In addition to the overall PCL score, we divided the scale into three subscales. The RT group had significantly lower Hypervigilance scores on average $(p<0.001)$, specifically at 3 months ( $p=0.002), 6$ months ( $p=0.001$ ), and 12 months $(p=0.003)$, as well as lower Intrusive Thoughts scores $(p=0.01)$, particularly at 9 months $(p=0.009)$. The interaction between RT and time was not significant ( $p=$ 0.16 ). The RT group did not have significantly different Avoidant Behavior scores on average $(p=0.08)$. 
Table 2.

Clinical characteristics of women with or without residential treatment (RT). Data presented as mean \pm standard deviation.

\begin{tabular}{|c|c|c|c|c|}
\hline Characteristic & No RT & 30-Day RT & $t$-Value & $p$-Value \\
\hline Social Support & $2.4 \pm 1.8$ & $2.7 \pm 2.0$ & 1.40 & 0.16 \\
\hline Symptom Checklist-30 & $2.5 \pm 0.9$ & $2.5 \pm 0.9$ & 0.02 & 0.98 \\
\hline \multicolumn{5}{|l|}{ PTSD Checklist } \\
\hline Total & $2.9 \pm 1.1$ & $2.9 \pm 1.2$ & 0.29 & 0.77 \\
\hline Hypervigilance Subscale & $3.1 \pm 1.1$ & $3.0 \pm 1.3$ & 0.96 & 0.33 \\
\hline Intrusive Thoughts Subscale & $2.6 \pm 1.2$ & $2.7 \pm 1.3$ & 0.39 & 0.70 \\
\hline Mental & $31.3 \pm 7.8$ & $35.9 \pm 7.6$ & 3.64 & 0.001 \\
\hline Physical & $32.0 \pm 5.4$ & $31.0 \pm 6.8$ & 0.98 & 0.33 \\
\hline \multicolumn{5}{|l|}{ ASI Scores } \\
\hline Psychiatric & $0.5 \pm 0.2$ & $0.5 \pm 0.2$ & 0.48 & 0.63 \\
\hline Drug & $0.1 \pm 0.1$ & $0.2 \pm 0.1$ & 8.03 & 0.001 \\
\hline
\end{tabular}

Table 3.

Follow-up experience of women with or without residential treatment (RT) by percentage of baseline participants completing follow-up interviews at different time points. Data presented as frequency, $n(\%)$.

\begin{tabular}{lrrrrr}
\hline \multicolumn{1}{c}{ Group } & $\begin{array}{c}\text { Baseline } \\
\boldsymbol{N}\end{array}$ & 3 Mo & $\mathbf{6}$ Mo & 9 Mo & $\mathbf{1 2}$ Mo \\
\hline No RT & 234 & $174(74)$ & $152(65)$ & $124(53)$ & $119(51)$ \\
30-Day RT & 217 & $192(88)$ & $144(66)$ & $115(53)$ & $96(44)$ \\
\hline \hline
\end{tabular}

The RT group had significantly higher scores on average for the Mental Health component of the SF-12 ( $p=0.003$ ), indicating better functioning, particularly at months $3(p=0.03)$ and $6(p=0.008)$. The RT group also had significantly higher scores on the Physical Health subscale in general $(p=0.002)$ but did not differ significantly at any single time point.

The RT group had significantly lower scores on average for the Psychiatric ASI scale $(p=0.04)$, specifically at 3 months $(p=0.005)$; however, the interaction between $\mathrm{RT}$ and time was nonsignificant ( $p=0.13$ ). The RT group had significantly higher scores on average on the ASI Alcohol scale $(p=0.03)$, controlling for baseline, particularly at 3 months $(p=0.01)$. However, the overall interaction between SS and time was nonsignificant $(p=$ 0.08 ). When looking at the days of alcohol use, we found that both groups had significantly decreasing days of use over time; however, the RT group had significantly higher use on average ( $p=0.03)$, controlling for baseline, but no particular time point was significantly different.
The RT group also had significantly higher scores on average for the ASI Drug scale $(p<0.001)$, controlling for baseline, particularly at 3 months $(p=0.01)$ and 6 months $(p=0.001)$. Both groups had significantly decreasing days of drug use over time; however, the RT group did not have a significantly different change in use ( $p=0.07)$, controlling for baseline.

\section{DISCUSSION}

These data indicate that in a relatively large sample of homeless female veterans, placement in RT for at least 30 days was associated with significantly improved clinical outcomes in a variety of domains. These associations did not appear to be explained by baseline differences in the characteristics of those who received RT, as might have been expected. As mentioned previously, about half of those veterans receiving services through a VA homelessness program are able to access RT and women who were placed into residential care were not very different at baseline from those who were not. This improved our ability to further control for baseline differences in multivariable models. The results show a clear advantage for those women who received RT, at least during the first year. It remains to be seen whether longer-term advantages exist once women are discharged from these programs and return to life in the community. 
JRRD, Volume 48, Number 8, 2011

Table 4.

Results of multivariable mixed models comparing residential treatment (RT) groups over time.

\begin{tabular}{|c|c|c|c|c|c|c|c|c|c|}
\hline \multirow{2}{*}{ Variable } & \multirow{2}{*}{ Group } & \multicolumn{4}{|c|}{ Least Square Means* } & \multicolumn{2}{|c|}{ RT Effect } & \multicolumn{2}{|c|}{$\mathbf{R T} \times$ Time } \\
\hline & & $3 \mathbf{M o}$ & $6 \mathrm{Mo}$ & 9 Mo & $12 \mathrm{Mo}$ & F-Value & $p$-Value & F-Value & $p$-Value \\
\hline \multirow[t]{2}{*}{ Days Worked, Past 30} & RT & 5.52 & 8.08 & 8.09 & 7.70 & 4.17 & 0.04 & 3.00 & 0.02 \\
\hline & NRT & 5.30 & 5.29 & 5.80 & 6.14 & & & & \\
\hline \multirow[t]{2}{*}{ Days Homeless, Past 30} & RT & 5.50 & 4.47 & 4.32 & 4.48 & 14.37 & $<0.001$ & 10.38 & $<0.001$ \\
\hline & NRT & 19.42 & 11.03 & 9.02 & 8.60 & & & & \\
\hline Social Support & RT & 3.28 & 3.45 & 3.60 & 3.76 & 19.11 & $<0.001$ & 7.09 & $<0.001$ \\
\hline \multirow[t]{2}{*}{ SCL } & RT & 2.11 & 2.13 & 2.06 & 1.92 & 18.04 & $<0.001$ & 4.63 & 0.001 \\
\hline & NRT & 2.40 & 2.35 & 2.32 & 2.26 & & & & \\
\hline \multirow[t]{2}{*}{ PCL } & RT & 2.72 & 2.68 & 2.63 & 2.57 & 10.31 & 0.001 & 1.97 & 0.09 \\
\hline & NRT & 2.97 & 2.98 & 2.82 & 2.84 & & & & \\
\hline Avoidant Behavior & RT & 2.70 & 2.61 & 2.59 & 2.58 & 3.10 & 0.08 & 0.96 & 0.25 \\
\hline \multirow[t]{2}{*}{ Hypervigilant } & RT & 2.80 & 2.76 & 2.74 & 2.61 & 14.55 & $<0.001$ & 3.38 & 0.009 \\
\hline & NRT & 3.14 & 3.14 & 2.92 & 3.04 & & & & \\
\hline \multirow[t]{2}{*}{ ASI Psychiatric } & RT & 0.43 & 0.45 & 0.44 & 0.41 & 4.27 & 0.04 & 1.77 & 0.13 \\
\hline & NRT & 0.49 & 0.46 & 0.46 & 0.45 & & & & \\
\hline \multirow[t]{2}{*}{ ASI Drug } & RT & 0.11 & 0.10 & 0.09 & 0.10 & 14.57 & $<0.001$ & 3.11 & 0.01 \\
\hline & NRT & 0.09 & 0.08 & 0.08 & 0.07 & & & & \\
\hline \multirow[t]{2}{*}{ Days of Drug Use, Past 30} & RT & 13.08 & 6.46 & 7.59 & 8.19 & 3.34 & 0.07 & 0.84 & 0.50 \\
\hline & NRT & 9.68 & 4.63 & 3.58 & 4.37 & & & & \\
\hline ASI Alcohol & RT & 0.22 & 0.19 & 0.19 & 0.19 & 4.86 & 0.03 & 2.11 & 0.08 \\
\hline SF-12 Physical & NRT & 33.20 & 32.88 & 32.92 & 32.09 & & & & \\
\hline
\end{tabular}

*Least square means are adjusted for baseline differences and other variables in model.

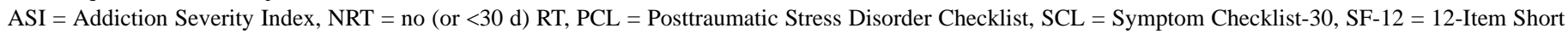
Form Health Survey.

It is also noteworthy that the results are quite robust despite wide variation in the types, sizes, and orientations of residential programs. There was consistency across programs in that all of them had at least some professional staff, the majority were gender-specific as opposed to coed, few allowed children to stay with their mothers in residence, and many were focused on addictions treatment. However, programs differed in the extent of clinical services-ranging from case management alone to inten- sive individual services in a variety of domains, from very small professional staffs with primarily peer-led groups to large professional staffs, and from Alcoholics Anonymous group models to intensive cognitive-behavioral treatment approaches.

Due to this wide variability and the general availability of VA outpatient services, it is possible that the most important characteristic of residential programs as opposed to other treatment approaches is the provision of 
stable safe housing for extended periods of time during the initial stages of recovery. Women who were not placed into a residential program had to secure shelter in some other way. A limited supply of Section 8 vouchers coupled with very high costs of living in many urban areas could make this a daunting task for any poor individual, let alone one who is suffering with psychiatric symptoms and/or problems with addiction.

Unfortunately, research suggesting that simply obtaining housing improves psychiatric outcomes is limited [21]. In part, this is due to the difficulty in conducting such research; it would be ethically dubious to randomize study participants to obtain housing or remain homeless. Additionally, in observational data, the direction of causality is often unknown - that is, study participants may have improved clinical outcomes as a result of obtaining housing or may have been able to secure housing because of improved psychiatric status. However, a few experimental [22] and quasi-experimental [23-24] studies suggest that homeless people who have serious mental illness who become stably housed have better psychiatric outcomes than people who do not become stably housed or who are housed in institutional settings.

It may thus be reasonable to hypothesize that having a safe and stable housing situation could be a key element, especially in the early stages of recovery for homeless women, many of whom have extensive histories of trauma and abuse [15]. Without an affordable and safe place to live, daily activities need to center around meeting basic needs and remaining safe, and few resources can be spared to get or remain sober or to deal with a psychiatric illness. RT services may thus be effective at substantially improving health and social adjustment in homeless women with psychiatric disorders.

These results should be viewed with several limitations in mind. First, because we did not randomize women to receive RT or not, some differences across the groups are likely. Most particularly, those entering residential programs are likely to have been more willing to be sober while a resident and commit to a long-term treatment program, requirements that may have been less stringent for other treatment options. However, on demographic and clinical characteristics, we did not find substantial differences across treatment groups and adjusted for these using multiple regression.

Second, "VA is a highly integrated healthcare system with similar rules and procedures at all facilities" [15]. This leaves it unclear how generalizable these results are to other, less integrated healthcare systems. However, since other studies, both observational as well as experimental, have found positive outcomes for homeless people in RT, we believe that our results would be generalizeable to homeless women both inside and outside VA.

We must also acknowledge that in this study substance use was only assessed by self-report interview and not verified by biochemical testing. "This may be particularly problematic because in most cases the client's clinician was the person conducting the research interview" [15]. Thus, if report of substance use may have resulted in an interruption of treatment and a loss of housing, selfreport results may have been biased. This would be likely to be truer of those in RT because of the regulations governing most programs. However, since we actually found significantly greater drug and alcohol use in the RT group, correcting for reporting biases would likely increase the magnitude of those differences.

Finally, the substantial loss to follow-up in this study limits our ability to make strong conclusions about the effects of RT beyond the limits of the study period itself. Future research should be focused on determining whether the short-term benefits of providing stable housing during recovery persist after clients move back into the community.

\section{CONCLUSIONS}

This study suggests substantial benefit from RT for homeless female veterans with psychiatric and/or substance abuse problems. The VA has been expanding its funding for RT to more fully address these needs. Though these programs represent somewhat more expensive services [13], they are associated with substantially improved clinical outcomes.

\section{ACKNOWLEDGMENTS}

\section{Author Contributions:}

Study design: I. Harpaz-Rotem, R. A. Rosenheck, R. Desai.

Data collection: R. Desai.

Data analysis: I. Harpaz-Rotem.

Drafting of manuscript: I. Harpaz-Rotem, R. A. Rosenheck, R. Desai. Obtained funding: R. A. Rosenheck, R. Desai.

Financial Disclosures: The authors have declared that no competing interests exist.

Funding/Support: This material is the result of work supported with resources and the use of facilities at the VA Office of Mental Health 
and the Mental Illness Research, Education, and Clinical Center, VA Connecticut Healthcare System, West Haven, Connecticut.

Institutional Review: Each participant gave written informed consent to participate in the study.

Participant Follow-Up: The authors do not plan to notify participants of the publication of this study because of a lack of contact information.

\section{REFERENCES}

1. Gamache G, Rosenheck R, Tessler R. The proportion of veterans among homeless men: A decade later. Soc Psychiatry Psychiatr Epidemiol. 2001;36(10):481-85.

[PMID: 11768845]

DOI:10.1007/s001270170012

2. Gamache G, Rosenheck RA, Tessler R. Overrepresentation of women veterans among homeless women. Am J Public Health. 2003;93:1132-36. [PMID: 12835198]

DOI:10.2105/AJPH.93.7.1132

3. Rosenheck R, Frisman L, Chung AM. The proportion of veterans among homeless men. Am J Public Health. 1994; 84(3):466-69. [PMID: 8129068]

DOI:10.2105/AJPH.84.3.466

4. Rosenheck R, Fontana A. A model of homelessness among male veterans of the Vietnam War generation. Am J Psychiatry. 1994;151(3):421-27. [PMID: 8109652]

5. Rosenheck R, Koegel P. Characteristics of veterans and nonveterans in three samples of homeless men. Hosp Community Psychiatry. 1993;44(9):858-63. [PMID: 8225299]

6. Rosenheck RA, Leda C, Gallup PG. Program design and clinical operation of two national VA programs for homeless mentally ill veterans. N Engl J Public Policy. 1992;8: 315-37.

7. Guydish J, Sorensen JL, Chan M, Werdegar D, Bostrom A, Acampora A. A randomized trial comparing day and residential drug abuse treatment: 18-month outcomes. J Consult Clin Psychol. 1999;67(3):428-34. [PMID: 10369064] DOI:10.1037/0022-006X.67.3.428

8. Lam JA, Jekel JF, Thompson KS, Leaf PJ, Hartwell SW, Florio L. Assessing the value of a short-term residential drug treatment program for homeless men. J Addict Dis. 1995;14(4):21-39. [PMID: 8929931] DOI:10.1300/J069v14n04_02

9. Conrad KJ, Hultman CI, Pope AR, Lyons JS, Baxter WC, Daghestani AN, Lisiecki JP Jr, Elbaum PL, McCarthy M Jr, Manheim LM. Case managed residential care for homeless addicted veterans. Results of a true experiment. Med Care. 1998;36(1):40-53. [PMID: 9431330]

DOI:10.1097/00005650-199801000-00006

10. Herrell JM, Fenton W, Mosher LR, Hedlund S, Lee B. Residential alternatives to hospitalization for patients with severe and persistent mental illness: Should patients with comorbid substance abuse be excluded? J Ment Health
Adm. 1996;23(3):348-55. [PMID: 10172714

DOI:10.1007/BF02522308

11. Fenton WS, Mosher LR, Herrell JM, Blyler CR. Randomized trial of general hospital and residential alternative care for patients with severe and persistent mental illness. Am J Psychiatry. 1998;155(4):516-22. [PMID: 9545998]

12. Hawthorne WB, Green EE, Gilmer T, Garcia P, Hough RL, Lee M, Hammond L, Lohr JB. A randomized trial of shortterm acute residential treatment for veterans. Psychiatr Serv. 2005;56(11):1379-86. [PMID: 16282256] DOI:10.1176/appi.ps.56.11.1379

13. Rosenheck R, Frisman L, Gallup P. Effectiveness and cost of specific treatment elements in a program for homeless mentally ill veterans. Psychiatr Serv. 1995;46(11):1131-39. [PMID: 8564501]

14. Kasprow WJ, Rosenheck RA, DiLella D, Cavallaro L, Harelik N. Health Care for Homeless Veterans (HCHV) programs: The 19th annual report. West Haven (CT): VA Northeast Program Evaluation Center; 2006.

15. Desai RA, Harpaz-Rotem I, Najavits LM, Rosenheck RA. Impact of the Seeking Safety Program on clinical outcomes among homeless female veterans with psychiatric disorders. Psychiatr Serv. 2008;59(9):996-1003.

16. McLellan AT, Luborsky L, Woody GE, O’Brien CP. An improved diagnostic evaluation instrument for substance abuse patients: The Addiction Severity Index. J Nerv Ment Dis. 1980;168(1):26-33. [PMID: 7351540] DOI:10.1097/00005053-198001000-00006

17. Derogatis LR. Brief Symptom Inventory: BSI; Administration, scoring, and procedures manual. Minneapolis (MN): Pearson; 1993.

18. Gandek B, Ware JE, Aaronson NK, Apolone G, Bjorner JB, Brazier JE, Bullinger M, Kaasa S, Leplege A, Prieto L, Sullivan M. Cross-validation of item selection and scoring for the SF-12 Health Survey in nine countries: Results from the IQOLA Project. International Quality of Life Project. J Clin Epidemiol. 1998;51(11):1171-78. [PMID: 9817135] DOI:10.1016/S0895-4356(98)00109-7

19. Ruggiero KJ, Del Ben K, Scotti JR, Rabalais AE. Psychometric properties of the PTSD Checklist-Civilian Version. J Trauma Stress. 2003;16(5):495-502. [PMID: 14584634] DOI:10.1023/A:1025714729117

20. Rosenheck RA, Leslie DL, Sindelar J, Miller EA, Lin H, Stroup TS, McEvoy J, Davis SM, Keefe RS, Swartz M, Perkins DO, Hsiao JK, Lieberman J; CATIE Study Investigators. Cost-effectiveness of second generation antipsychotics and perphenazine in a randomized trial of treatment for chronic schizophrenia. Am J Psychiatry. 2006;163(12): 2080-89. [PMID: 17151158]

DOI:10.1176/appi.ajp.163.12.2080

21. Kyle T, Dunn JR. Effects of housing circumstances on health, quality of life and healthcare use for people with severe mental illness: A review. Health Soc Care Community. 
2008;16(1):1-15. [PMID: 18181811]

DOI:10.1111/j.1365-2524.2007.00723.x

22. Lipton FR, Nutt S, Sabatini A. Housing the homeless mentally ill: A longitudinal study of a treatment approach. Hosp Community Psychiatry. 1988;39(1):40-45.

[PMID: 3338726]

23. Hodgins S, Cyr M, Gaston L. Impact of supervised apartments on the functioning of mentally disordered adults. Community Ment Health J. 1990;26(6):507-16.

[PMID: 2286056]

DOI:10.1007/BF00752455

24. Clark C, Rich AR. Outcomes of homeless adults with mental illness in a housing program and in case management only. Psychiatr Serv. 2003;54(1):78-83. [PMID: 12509671] DOI:10.1176/appi.ps.54.1.78
Submitted for publication October 12, 2010. Accepted in revised form March 22, 2011.

This article and any supplementary material should be cited as follows:

Harpaz-Rotem I, Rosenheck RA, Desai R. Residential treatment for homeless female veterans with psychiatric and substance use disorders: Effect on 1-year clinical outcomes. J Rehabil Res Dev. 2011;48(8):891-900.

DOI:10.1682/JRRD.2010.10.0195

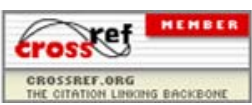


